Research Article

www.jestr.org

\title{
Joint Venture Modes of Water Conservancy and Hydroelectric Engineering
}

\author{
Zhiding Chen" and Zhudi Sheng \\ College of Hydraulic \& Environmental Engineering, China Three Gorges University, Yichang, China
}

Received 15 May 2013; Accepted 25 July 2013

\begin{abstract}
With the long construction period, the giant scope and complex technology, water conservancy and hydroelectric engineering construction has large investment. In the fully competitive water conservancy and hydropower project construction contracting market, it is almost impossible for a company to contract with a water conservancy and hydropower project independently. Therefore, water conservancy and hydropower project construction can be contracted by several construction companies together, to play each company's strengths, lower offer, improve project quality, shorten the construction period and win the competition. In this paper, we started from the definition of Joint Venture, summed up the forms of Joint Venture in water conservancy and hydropower engineering, proposed that the JV modes can be divided into domestic and international union, tight mode, half-tight mode, loose mode, incorporation and consortium. Furthermore, we analyzed the advantages and disadvantages of Joint Venture. Put forward that the JV can relieve the owner from interfacial administrative work, reduce risk of engineering, and raise the success rate of engineering contract, improve the correctness of price and increase the opportunity of project contracting, Learn from other members, enhance technology and management and make full use of idle resources
\end{abstract}

Keywords: Water conservancy and hydroelectric engineering, Joint Venture mode, Analysis

\section{Introduction}

Joint Venture mode ( $\mathrm{JV}$ mode) is widely used in the international construction market, which is particularly suitable for large-scale engineering constructions [1][2]. Qinghua He quotes the classified statistic data of contract price in the New Hong Kong International Airport, and illustrates the universality of contracting large-scale projects with joint contract format in international market. He also proposes the selecting criteria for joint contract partners, analyzes the three basic formats of the contemporary internationally accepted joints are provided. Furthermore, he presents the analyses of the way to form the agreement before bidding, to compose the bid and quotation, to determine the contract agreement of joints [3]. Xiaoping Gou investigates the contractors of joint venture should bear the unlimited liability or limited liability, and also analyzes engineering insurance system [4]. Several international construction joint ventures (ICJVs) have failed achieving time, cost and quality targets because of lack of an appropriate risk assessment methodology. Therefore, a simplified decision support system (RAMSCO) is proposed that breaks down project risks into discrete phases systematically [5]. Constructors are facing, constantly, complicated problems occasioned by culture, frequent policy changes, and other related factors when conducting Joint Ventures (JVs) in Mainland China. Sung-Lin Hsueh et al. applied Analytical Hierarchy Process (AHP) and Utility Theory to develop a multi-criterion risk assessment model for construction pre-JVs stage and to integrate World Wide

\footnotetext{
*E-mail address: Chen_zhiding@163.com

ISSN: 1791-2377 @ 2013 Kavala Institute of Technology. All rights reserved.
}

Web (WWW) and company Databases [6]. Gerhard Girmscheid, M.ASCE and Christian Brockmann proposed that trust is a mechanism that allows to reach goals efficiently within this setting. As a consequence, they can find a special form of trust in international construction joint ventures: necessitated general trust that is extended to everyone even without prior knowledge [7]. Xianbo Zhao et al. aims to assess the risks associated with the underground rail ICJVs in Singapore. To achieve this objective, a comprehensive literature review was carried out and a questionnaire survey was conducted with 33 contractors. With the help of this study, ICJV partners can identify the most critical risks and thus develop mitigation measures. Also, the findings from this study provide a comprehensive picture of risks for the companies that intend to participate in ICJVs in Singapore [8].

Most water conservancy and hydroelectric engineering constructions are cross-departmental and cross-sectoral, trans-regional national projects[9], such as the Three Gorges dam, Xiluodu, Xiangjiaba, Ertan, Xiaolangdi, etc, which had the problems including large scale, huge investment, difficult in construction, high technology, it is difficult to complete by a single company, thus the JV mode was used in most projects. Cases of using JV mode in domestic water conservancy and hydroelectric engineering constructions have been increasing year by year since the 1980's. On August 19, 1993, a lot of water conservancy and hydroelectric enterprises came to the Three Gorges Project and considered how to do their best to meet the challenges, which made win-win co-operation of 378 born in domestic water and electricity construction enterprise. Some surveys showed that JV mode had been used in many cases in the 
world, not only the companies in America but also in Japan and Europe had increased by 30 times in the past decades. It can be accepted that the tendency will continue into $21 \mathrm{st}$ century.

\section{Joint venture modes}

JV is short for Joint Venture, originated from manufacturing industry, in which Joint venture is mainly to establish subcompanies and called Joint Enterprise or Partnership Business [10]. JV also had different names in construction industry, such as it was called Joint Venture or Consortium in Europe and America; Common enterprise in Japan; Joint contact, Joint manage or Short-term Joint in Taiwan.

Article 27 of the China Construction Law provides that the large-scale or complex engineering can be contracted by over two contractors; article 31 in the Bidding Law of China also shows that more than two legal entities or other organization can constitute a combo to bid as a bidder. Item 1 , article 42 in the Measures for Tendering and Bidding for Engineering Construction Projects, and item 1, article 38 of the Measures for Bidding about Goods for Engineering Construction Projects set the similar provisions. These have clarified the definition of joint venture that is more than two legal persons or other organization which can implement accounting independently, undertake civil liability and engineering projects as well as make up a new combo to contract engineering projects as a contactor. If the combo wins the bidding when the projects are in the specific operation process, joint bidding will transform into joint venture.

\section{Form of JV}

JV develops from business activities. The form of JV also changes with different type, scale and other economic situation of engineering. In fact, each form of JV is based on the agreement of partners.

\subsection{Classification by country of the partner companies}

Joint venture can be classified into domestic union and international union by whether the joint companies come from a same country or not.

\subsubsection{Domestic union}

$\mathrm{JV}$ can be classified into domestic union and international union by whether the joint companies come from a same country or not.

Domestic union is such kind of JV that the joint companies come from the same country. In China, most domestic combos belong to this type. Such as the combo of 378 and Qingyun company who won the bidding in the construction of the Three Gorges Projects .The OTFF who took responsibility for the construction of Xiaolangdi Project in Yellow River composes of water conservancy and hydroelectric the First, Third, Fourth and Fourteenth engineering companies. Being successful in cable foundation and dam foundation (above $1 \mathrm{~km}$ elevation) excavating, supporting and related work on right bank of Xiaowan hydropower station was hydroelectric the Forth bureau associated with the Third bureau. It cost five hundred and seven million yuan to win the bidding on left bank of Xiaowan hydropower station in Yunnan was joint group of the Eighth bureau, the Seventh bureau and Gezhou Dam Group.

\subsubsection{International union}

International union is combined by companies from different countries, or by foreign companies and local ones. Such as the CGIC (China-German-Italian Combo) who won the bidding of Xiaolangdi Project in Yellow River, SGEJV who won the bidding of underground factory of Ertan, the ChinaItaly combo who contracted the dam building of Ertan. These are international joint.

\subsection{Classification by the relationship between the contracted entities}

Depending on the organization, internal economic relationship, JV can be classified into tight, half-tight, and loose modes.

\subsubsection{Tight mode}

In this mode, all partners share the investments, interests, risks, management together. Tight mode is a kind of legal person mode, who is a limited liability entity and is responsible for external civil affairs according to related law by all its' owns or authorized management of property.

\subsubsection{Half-tight mode}

Depending on the nationality of the combined entity and the available laws, Half-tight Mode can be classified into international bidding combo of domestic engineering and domestic engineering combo.

\subsubsection{Loose Mode}

Loose Mode regards the joint contract as the only link, for the purpose of accomplishing their respective economic interest. According to the Contract Law, Architecture Law, and the Bidding Law, the members of combo should undertake joint responsibility. The loose mode combo only takes responsibility for the agreements instead of the law, nor joint responsibility.

3.3 Joint venture is classified into incorporation and consortium depending on the way of management

3.3.1. Incorporation

By all members co-invest to establish a new incorporation with legal personality who can contract a certain project, any resource needed will provided by the new incorporation, and there is no legal relationship between the new incorporation and its mother contractor, each mother company works independently from the influence of the new incorporation(e.g figure 1). This form is often dismissed after the project finished.

\subsubsection{Consortium}

\section{i) Joint named}

The partners sign their name on the contract and take joint responsibility for the owner (e.g figure2), all members have direct contractual relationship with the owner, also have equal status, that is to say they co-manage a project. In addition, because each of them takes responsibility respectively during the operation of projects, so lack of 
uniformity in the implementation of business which results in inconsistent things.

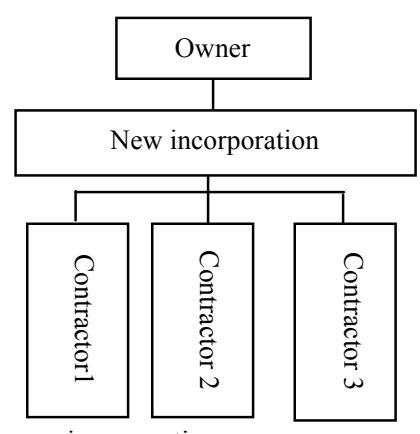

Fig.1. Establish a new incorporation.

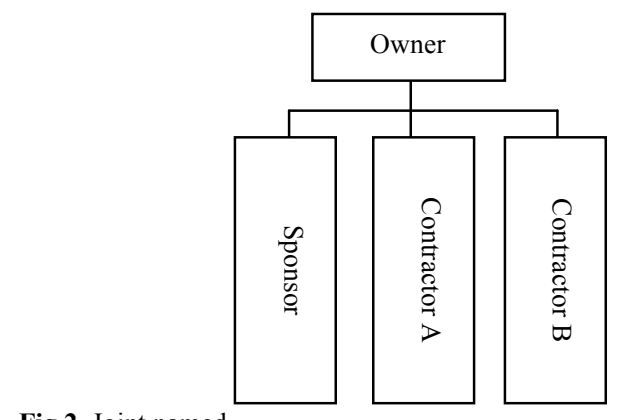

Fig.2. Joint named.

ii) Recommending Sponsor

All partners put their name on the contract and recommend a sponsor who is usually the manufacturer with the largest investment proportion. The sponsor is in the name of contract in external. In fact, the internal operation and management is undertaken by all members. Sometimes, the management authorities are transferred to the representative company, while other members are not directly involved in the project implementation and only provide funds or staffs and machines (e.g figure 3). The other is that all members make up a management committee who is in charge of the internal operation, a project manager will be appointed to be responsible for the project implementation (e.g figure 4).

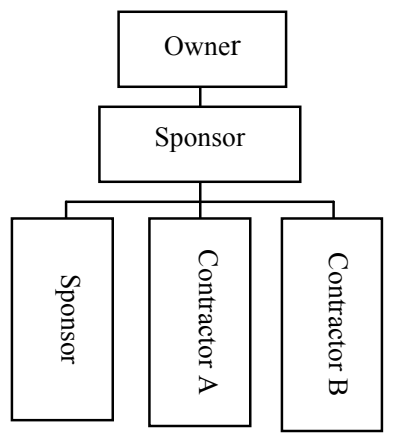

Fig.3. Sponsor

\section{The advantages and disadvantages of joint venture}

\subsection{Advantages of joint venture}

4.1.1 Joint venture can relieve the owner from interfacial administrative work, reduce risk of engineering, and increase the success rate of engineering contract
As for the owner, if it was separated to several bidders due to the technical difficulties or scale, the owner have to be in charge of interfacial integration himself or entrust an agent after separating, that is to say the management difficulties will increase for the owner. If the owner allows the contractor to joint contract, the technicality and diversity of JV will increase after proper combination, thus the owner could reduce the quantity of project and management work .Delivering the interfacial administrative work to cocontractor. Owing to the owner just needs to manage joint body, which lowers the risk of management. At the same time, co-contractors can combine freely, complement with each other, coordinate work independently, and reduce the engineering dispute. Each member takes joint responsibility for the owner, in case of the joint companies go bankrupt or happen other important event that result in being unable to keep the appointment, other members find another contractor who has the qualification in common to share the rights and obligations depending on the terms of contract. The owner can lower the risk of engineering which the contractor can't keep the appointment. For the large engineering projects, because of the complex technology, long construction period and construction difficulty, in general, a single professional construction enterprise has difficulty in completing a project. JV mode combines more than two enterprises with complementary advantage to bid, which will improve competitive power of the bidding enterprise, and make more enterprise participate in bidding, thereby will increase the success rate of engineering contract.

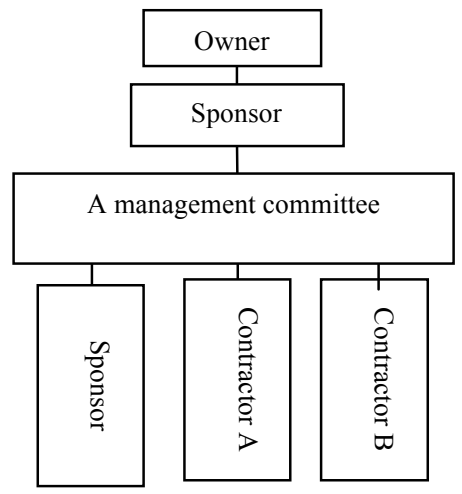

Fig.4. A management committee.

\subsubsection{Benefits of joint venture to each member company}

i) Reducing risks

Water conservancy and hydroelectric is the high-risk industry, especially the large-scale ones. Because of long construction period and huge investment that result in suffering harder strike than the other projects from risks, such as policy changes, labor, shortages in labor and material, price, exchange rate, etc. these will be hard for a single contractor. While in joint venture mode, all members can support each other, disperse risks and reduce losses.

ii) Improving the correctness of price and increasing the opportunity of project contracting

With the large scale and high complexity of the water conservancy and hydroelectric engineering, the correctness of price affects the profits directly, so the contractors will figure out the quote of their own part before bidding, and check and modify with each other, they can increase the correctness of price, prevent mistakes or omissions, reduce losses caused by wrong quotes. On the other hand, JV can be 
adopted when the contractors are short of finance or performance, and by prequalification to increase the chance to contract.

iii) Learning from other members, enhancing technology and management

Owing to engineering construction often need new processes and technologies, which contractors can learn advanced technology and management from other members in the construction through joint venture mode, especially in the international projects, the member companies can learn new technology and process from the foreign contractors, thereby enhance the domestic contractors' technical level and management level.

iv) Making full use of idle resources

When a contractor has excess or idle construction equipment or resources, which are of benefit to engineering construction, these could be used as a part of the financial contribution, and undertake the engineering with other contractors.

\subsection{Disadvantages of joint venture}

\subsubsection{False agreement}

In the joint venture, some enterprises sign the false agreement in order to obtain the project in competition. If the false union wins the bidding, it will bring a lot of risks for the project management, even be unable to finish the projects.

\subsubsection{Increasing the workload in checking qualification}

According to Joint venture form to bid a project, a bid needs to check many enterprises in qualification, namely every member's qualification must be checked, which will increase the job of checking.

\subsubsection{Difficulties in cooperation}

In joint venture mode of water conservancy and hydroelectric engineering, because the members have different abilities and are easy to contain with each other, every member has more difficulty in reaching agreement. What's more, JV is a temporary organization, which makes it hard to promote the construction efficiency. Some members also worry that the day of success is the time of disintegration, which increase more difficulties in cooperation.

\section{Conclusions}

Joint venture mode is widely used in the world, especially after Chinese construction market opened to the international contractors. In the circumstance of a globalize market, the competition of domestic construction market become even fiercer due to the participation of foreign contractors, the water conservancy and hydroelectric enterprise will have more advantages through JV mode. At the same time, domestic enterprises also shall go abroad and seek projects and look for new development space from the international market through combining with local contractors.

\section{References}

1. Badger.W.W and Mulligan D.E, "Rationale and Benefits Associated with International Alliances", Journal of Construction Engineering and Management121,1995, pp.100-111.

2. Beliz Ozorhon, David Arditi, Irem Dikmen, and M. Talat Birgonul, "Performance of international joint ventures in construction", Journal of Management in Engineering 26(4), 2010, pp.209-222.

3. Qinha He, "Organization of Joint Contract in Large-scale Construction Project", Construction Technology 28(11),1999, pp.40-41.

4. Gou Xiaoping, "the Discussion for Legal Question of JV", Journal of Hubei social sciences 06, 2003, pp.92-93.

5. Abdelghany, Y. and Ezeldin, A, "Classification of Risks for International Construction Joint Ventures (ICJV) Projects", Construction Research Congress, 2010, pp. 1254-1263.

6. Sung-Lin Hsueha, Yeng-Horng Perngb, Min-Ren Yanc, and JenRong Leed, "On-line multi-criterion risk assessment model for construction joint ventures in China", Automation in Construction 6(5), 2007, pp.607-619.
7. Gerhard Girmscheid, and Christian Brockmann, "Inter- and Intraorganizational Trust in International Construction Joint Ventures", Journal of Construction Engineering and Management 136(3), 2010, pp.353-360.

8. Xianbo Zhao, Bon-Gang Hwang, and Gwendolyn Shiyun Yu, "Identifying the critical risks in underground rail international construction joint ventures: Case study of Singapore", International Journal of Project Management 31, 2013, pp.554-566.

9. Chen, Zhiding,"Game model for project bidding of cross-industry based on information", 1st International Conference on Information Science and Engineering, 2009, pp. 4313-4315.

10. David N. Sillars and Roozbeh Kangari, "Predicting Organizational Success within a Project-Based Joint Venture Alliance", Journal of Construction Engineering and Management 130, 2004, pp.500-508 